Marie-Odile Pittin-Hédon, The Space of Fiction. Voices from Scotland in a Post-Devolution Age Glasgow, Scottish Literature International, 2015, 206 p.

\title{
Camille Manfredi
}

\section{OpenEdition}

\section{Journals}

Édition électronique

URL : http://journals.openedition.org/etudesecossaises/1139

DOI : 10.4000/etudesecossaises. 1139

ISSN : 1969-6337

Éditeur

UGA Éditions/Université Grenoble Alpes

Édition imprimée

Date de publication : 25 avril 2016

Pagination : 167-168

ISBN : 978-2-84310-324-7

ISSN : $1240-1439$

Référence électronique

Camille Manfredi, « Marie-Odile Pittin-Hédon, The Space of Fiction. Voices from Scotland in a Post-

Devolution Age », Études écossaises [En ligne], 18 | 2016, mis en ligne le 01 janvier 2017, consulté le 16 mars 2021. URL : http://journals.openedition.org/etudesecossaises/1139 ; DOI : https://doi.org/ 10.4000/etudesecossaises. 1139 


\section{RECENSIONS}

\section{Camille Manfredi}

Université de Bretagne occidentale

Marie-Odile Pittin-Hédon, The Space of Fiction. Voices from Scotland in a PostDevolution Age, Glasgow, Scottish Literature International, 2015, 206 p.

Publiée par l'ASLS, cette récente monographie de Marie-Odile PittinHédon, professeur en études écossaises et études britanniques contemporaines à l'université d'Aix-Marseille, propose une lecture fine et exhaustive des voies qu'ouvrent les auteurs de la nouvelle scène littéraire écossaise en contexte post-dévolutionnaire. Dans The Space of Fiction. Voices from Scotland in a Post-Devolution Age, Marie-Odile Pittin-Hédon explore le large spectre dans lequel se déploient les littératures écossaises du XXI siècle et examine les déplacements de curseur entre l'artistique, le politique et l'idéologique qu'opère cette nouvelle génération d'auteurs. La métaphore spatiale annoncée en titre permet d'envisager la fiction écossaise contemporaine comme un territoire toujours mouvant et les expérimentations formelles des auteurs comme autant de passages, voire abolitions, des frontières géographiques, linguistiques et, ce qui intéresse particulièrement l'auteur, génériques.

L'ouvrage dont on saluera la grande rigueur scientifique s'attache ainsi à réévaluer la force des canons (un sujet à la sensibilité renouvelée, comme le démontre l'auteur en introduction) et le jeu des continuitésdiscontinuités entre la seconde renaissance littéraire écossaise (Gray, Kelman, Galloway...) et les auteurs de ce qu'Eleanor Bell et Gavin Miller qualifiaient en 2004 d'âge «post-national». À l'examen de chacune des nombreuses œuvres de son corpus, Marie-Odile Pittin-Hédon envisage le traitement du genre et de la forme comme un indice des tensions entre nationalisme et transnationalisme, localisme et multiculturalisme qui animent le paysage littéraire écossais. Chaque chapitre met en lumière un glissement normatif au sein d' «espaces» fictionnels et génériques dont il s'agit, pour les jeunes auteurs écossais, de tester les frontières tout en assurant à la littérature écossaise une plus grande visibilité à l'échelle européenne et mondiale.

Le premier chapitre, «Millenium Babes», s’intéresse à l'écriture de la ville par les romancières Laura Hird, Anne Donovan, Zoë Strachan et 
Alison Miller et à leur réappropriation d'un locus qu'avaient contribué à baliser James Kelman et Irvine Welsh à la fin du $\mathrm{xx}^{\mathrm{e}}$ siècle. Dans le chapitre deux, «Female crime fiction: the space of transgression», MarieOdile Pittin-Hédon se penche sur les romans de détection de Louise Welsh, Val McDermid et Denise Mina pour mettre en lumière les modalités d'inflexion par la voix féminine d'une littérature écossaise de genre (policier et gothique) déterminée à ne pas se laisser fossiliser. Les chapitres suivants sont consacrés à l'entreprise de dés-invention puis réinvention du passé et du territoire écossais (James Robertson), à la représentation du multiculturalisme, des questions linguistiques qui en découlent (Suhayl Saadi) et au traitement en littérature de l'entrée de l'Écosse dans le marché mondialisé (Ewan Morrison). Nourri de ces considérations, le dernier chapitre «The confines of the Human» explore le traitement du «cosmopolitisme» depuis la dialectique individu-collectivité dans les nouvelles de Michel Faber, Des Dillon, Suhayl Saadi, Dilys Rose et bien d'autres.

The Space of Fiction propose une réflexion approfondie et actualisée des littératures écossaises du Xxi siècle. Dans cet ouvrage qui ne tardera pas à devenir de référence, Marie-Odile Pittin-Hédon fait la démonstration du dynamisme d'une nouvelle scène littéraire écossaise attachée à travailler l'élasticité de l'écart entre des problématiques dites «nationales» (si tant est qu'elles puissent n'être que cela) et celles qui débordent les seules frontières de l'Écosse.

Silke Stroh

University of Muenster

Klaus Peter Müller (ed.), Scotland 2014 and Beyond - Coming of Age and Loss of Innocence?, Frankfurt am Main, Peter Lang, 2015, 457 p.

Structured around the central nexus of the Scottish independence referendum of 18 September 2014, this interdisciplinary volume investigates a wide range of cultural and social issues which have pertained to the independence debate, and to the wider developments that led up to it. As the word "beyond" in the book title indicates, the collection also discusses prospects for the country's post-referendum future. Although the referendum result turned out a 55-percent vote in favour of staying within the UK, it soon became clear that Scottish nationalism and the demand for 